\title{
Pengaruh Penambangan Batu Gamping Terhadap Kondisi Lahan dan Air Tanah Dalam di Desa Bedoyo, Kecamatan Ponjong, Kabupaten Gunung Kidul, Yogyakarta
}

\author{
Kristina Busira \\ Magister Teknik Lingkungan, Fakultas Teknik Sipil dan Perencanaan, \\ Institut Teknologi Adhi Tama Surabaya, Surabaya, Indonesia \\ Email: kristinasenjabusira@gmail.com
}

\begin{abstract}
It is necessary to improve the quality of research referring to the improvement of the relevance of research and scientific development. The potential of limestone is very large in Bedoyo village, Gunung Kidul sub-district, Yogyakarta can improve social and economic conditions for the local community, mining can also have a big impact, namely the surface of the mining area is damaged so that erosion is easier, even the impact of limestone mining on water. Research objectives: (1) Knowing the level of environmental damage in the form of erosion rates caused by limestone mining in Bedoyo village, (2) Knowing the direction of land conservation priorities, and (3) Knowing the effect of limestone mining activities on the depth of groundwater in Bedoyo village. The research method in this study consists of two parts, namely: (1) The research method for environmental damage uses the Universal Soil Loss Equation (USLE) method, the factors made in the calculation are rain erosivity $(R)$, erodibility $(K)$, length and slope $(L S)$, vegetation $(C)$, conservation measures (P), and (2) research methods for groundwater depth using the geoelectric resistivity method of the Schlumberger configuration. The results of the study on the level of environmental damage based on the rate of erosion, the research area in Bedoyo village was included in the normal, moderate, and very heavy erosion hazard classes, with the highest erosion of 21,501,849 tons/ha/year found on land near the mining area. Meanwhile, in the geoelectrical study of the Schlumberger configuration, the data obtained that the shocking point 2 is in the aquifer depth of 0.41-30.32 meters and the sounding point 3 with a depth of 0.60-31.76 meters.
\end{abstract}

Keywords: Erosion, Groundwater depth, Schlumberger configuration, USLE method

\begin{abstract}
Abstrak
Potensi batu gamping sangat besar di Desa Bedoyo, Kecamatan Gunung Kidul, Yogyakarta dapat meningkatkan kondisi sosial dan ekonomi bagi masyarakat setempat. Penambangan tersebut juga dapat menimbulkan dampak besar yaitu permukaan lahan pertambangan yang rusak sehingga lebih mudah mengalami erosi, bahkan dampak dari penambangan batu gamping pada air. Tujuan penelitian: (1) Mengetahui tingkat kerusakan lingkungan, berupa laju erosi yang disebabkan oleh penambangan batu gamping di Desa Bedoyo, (2) Mengetahui arahan prioritas konservasi lahan, dan (3) Mengetahui pengaruh kegiatan penambangan batu gamping terhadap kedalaman air tanah di Desa Bedoyo. Metode penelitian pada penelitian ini terdiri dari dua bagian, yaitu: (1) Metode penelitian untuk kerusakan lingkungan menggunakan metode Universal Soil Loss Equation (USLE), faktor yang dibuat dalam perhitungan adalah erosivitas hujan $(R)$, erodibilitas $(K)$, panjang dan kemiringan lereng $(L S)$, vegetasi $(C)$, tindakan konservasi $(P)$, dan (2) Metode penelitian untuk kedalaman air tanah menggunakan metode geolistrik resistivitas konfigurasi Schlumberger. Hasil penelitian tingkat kerusakan lingkungan berdasarkan laju erosi, daerah penelitian di Desa Bedoyo, termasuk dalam kelas bahaya erosi normal, moderat, dan sangat berat, dengan erosi tertinggi sebesar 21.501.849 ton/ha/tahun terdapat pada lahan dekat daerah tambang. Sedangkan pada penelitian geolistrik, konfigurasi Schlumberger diperoleh data titik shounding 2 berada di kedalaman akuifer 0,41-30,32 meter dan titik sounding 3 dengan kedalaman 0,60-31,76 meter.
\end{abstract}

Kata kunci: Erosi, Kedalaman air tanah, Konfigurasi Schlumberger, Metode USLE 


\section{Pendahuluan}

Desa Bedoyo adalah salah satu desa yang masuk pada administrasi Kecamatan Ponjong di Kabupaten Gunung Kidul, Yogyakarta. Desa tersebut memiliki potensi material industri terutama bahan galian batu gamping yang sangat besar. Potensi batu gamping yang sangat besar ini dimanfaatkan oleh berbagai manusia untuk melakukan kegiatan penambangan karena dapat meningkatkan kondisi sosial dan ekonomi bagi masyarakat setempat. Namun, pada penambangan tersebut juga dapat menimbulkan dampak besar, yaitu permukaan lahan pertambangan yang rusak serta miliki kemiringan dinding galian yang sangat curam sehingga lebih mudah terjadinya erosi. Bahkan, dampak dari penambangan terhadap air yaitu sulitnya mendapatkan air tanah.

Proses hilang, terkikisnya tanah dari tempat lain yang terangkut oleh air, angin menuju tempat yang lain dinamakan erosi [1]. Air tanah sangat berperan penting karena pemenuhan kebutuhan pokok banyak orang terutama adalah sumber air. Eksplorasi atau pencarian sumber air tanah penting dilakukan sehingga dapat mengetahui ada dan tidaknya akuifer (lapisan pembawa air). Manrulu [2] perbandingan antara bidang yang tidak terisi dengan seluruh volume batuan dan dinyatakan dengan satuan persen, sedangkan permeabilitas adalah tanah atau batuan yang mampu dilewati oleh air. Semakin berkembangnya aktivitas penambangan batu gamping akan berdampak pada kerusakan lahan, turunnya potensi air tanah dan kondisi sosial-ekonomi penduduk [3], sehingga tujuan pada penelitian ini yaitu untuk mengetahui tingkat kerusakan lingkungan yang terjadi akibat penambangan batu gamping, arahan konservasi lahan, dan mengetahui pengaruh penambangan batu gamping terhadap kedalam lapisan air tanah (akuifer).

\section{Metode}

Penelitian dilaksanakan di Desa Bedoyo, Kecamatan Ponjong, Kabupaten Gunung Kidul, Daerah Istimewa Yogyakarta. Pengambilan sampel tanah dilakukan pada 10 titik. Adapun titik sounding geolistrik dilakukan pada tiga titik, mulai dari koordinat 110.72499 E $08.01560 \mathrm{~S}$ 110.73103 E 08.01059 S.

Metode penelitian pada penelitian ini terdiri dari dua bagian, yaitu: (1) Metode penelitian untuk kerusakan lingkungan menggunakan metode Universal Soil Loss Equation (USLE), dan (2) Metode penelitian untuk kedalaman air tanah menggunakan metode geolistrik resistivitas konfigurasi Schlumberger. Sampel tanah yang diambil menggunakan cara atau metode random sampling. Cara pengambilan sampel acak adalah teknik sederhana dan praktis untuk mengukur ketidakpastian (deviasi standar) dari parameter target yang dihitung dengan kode analisis inti (Tomohiro Endo et all, 2015).

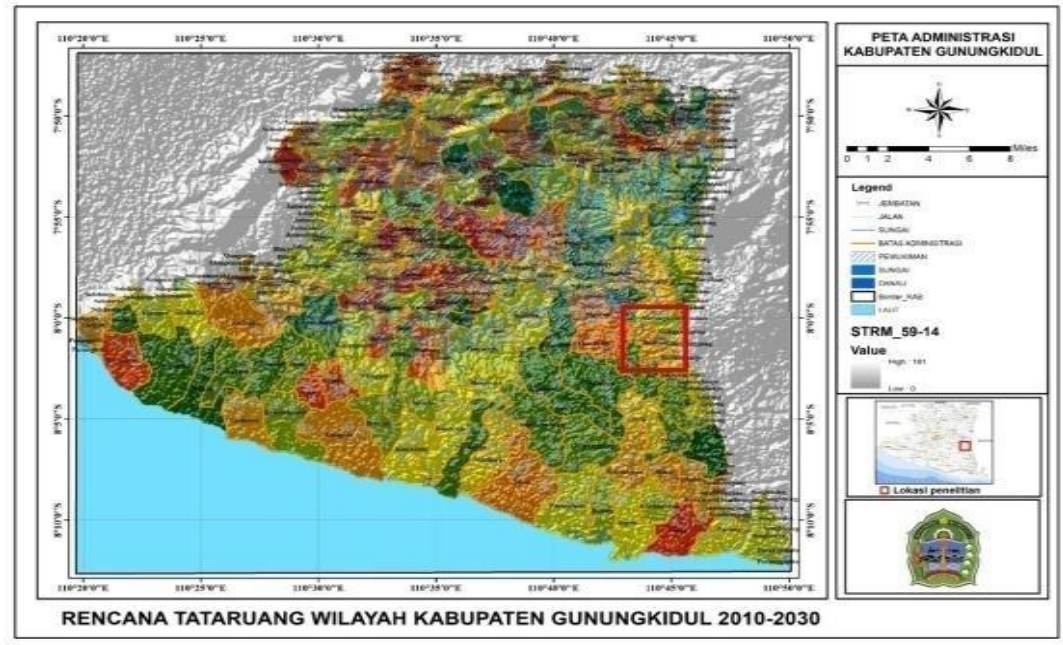

Gambar 1. Peta Kesampaian Daerah

Empat buah elektroda digunakan untuk konfigurasi Schlumberger, elektroda P1 dan P2 berada di tengah antara elektroda $\mathrm{C} 1$ dan $\mathrm{C} 2$. Setelah dilakukan pengukuran pertama, elektroda $\mathrm{C} 1$ dan $\mathrm{C} 2$ 
digeser menjauhi P1 dan P2 sejauh $a$, sampai jarak tertentu dengan variasi spasi elektroda $(a)$ 0,5 m; $2,5 \mathrm{~m} ; 5 \mathrm{~m} ; 10 \mathrm{~m} ; 25 \mathrm{~m}$; dan $50 \mathrm{~m}$. Proses pengambilan data dilakukan di tiga titik sounding.

Dua puluh sampel yang diambil dari lokasi penelitian kemudian dilakukan pengujian pada Laboratorium Balai Pengkajian Teknologi Pertanian (BPTP) Maguwoharjo, Kabupaten Sleman, Yogyakarta. Pengujian laboratorium ini bertujuan untuk mendapatkan nilai tekstur tanah, kandungan C-organik, dan permeabilitas tanah.

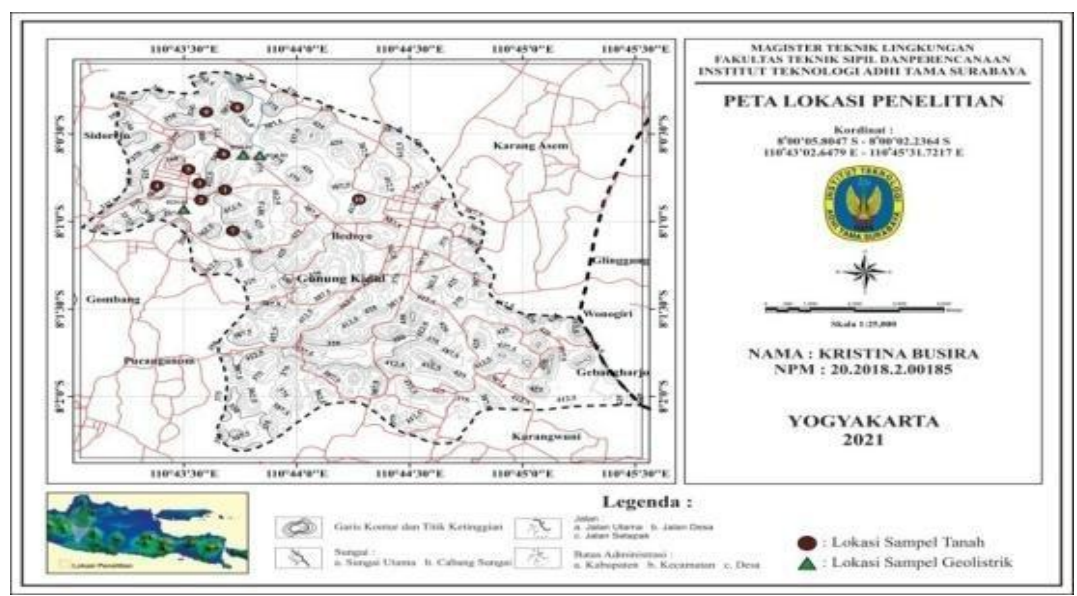

Gambar 2. Peta Lokasi Penelitian

\section{Hasil dan Pembahasan}

Berdasarkan data DEM dan SRTM daerah penelitian adalah daerah yang memiliki variasi kemiringan lereng mulai dari lereng datar sampai sangat curam. Daerah penelitian sebagian besar adalah daerah dengan kemiringan $16,66-25 \%,>25-35,71 \%$.

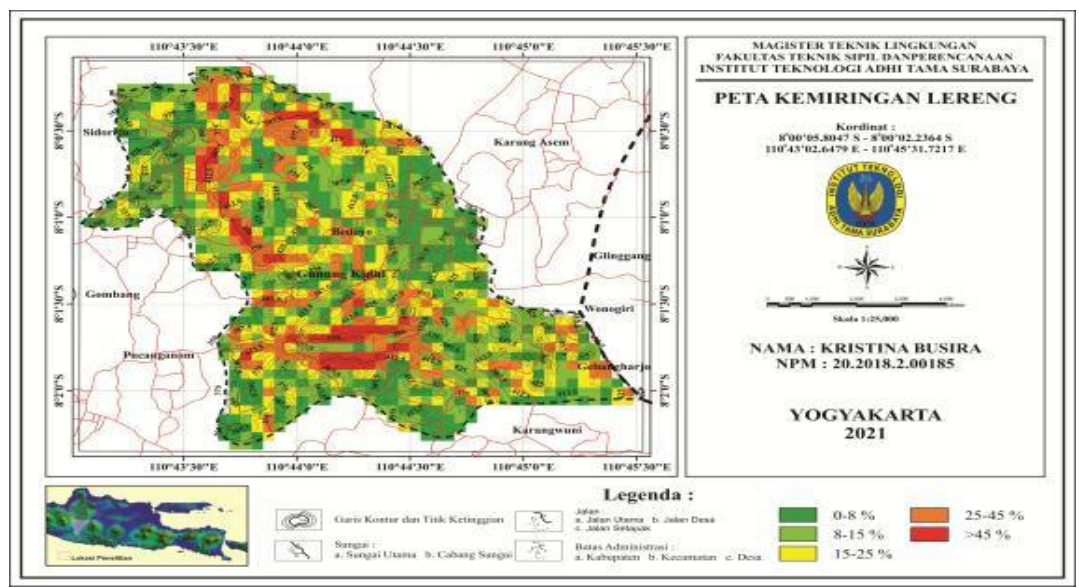

Gambar 3. Peta Kemiringan Lereng

Analisis Laboratorium Tekstur meliputi pasir, debu dan liat serta analisa C-organik. Sampel di berikan keterangan Lp1 - Lp10. Lp1 (42, 27, 31, 1.87), Lp2 (6, 23, 71, 1.37), Lp3 (13, 31, 56, 1.88), Lp4 (28, 36, 36, 2.01), Lp5 (4, 25, 71, 1.75), Lp6 (2, 26, 72, 1.63), Lp7 (7, 19, 74, 1.85), Lp8 (44, 24, 32, 2.29), Lp9 (2, 28, 70, 1.48) dan Lp10 (38, 29, 33, 1.16).

Pengelolaan tanaman didaerah pengamatan ditemukan lima macam nilai pengelolaan tanaman (C) seperti, terbuka (C) 1, Alang-alang murni subur (C) 0,001, Jagung (C) 0,7, hutan produksi tebang pilih (C) 0,2 dan kebun campur. Cara mendapatkan niai (C) ialah dengan menjumlahkan nilai indeks faktor vegetasi dan membagikan dengan jumlah sampel. 
Tindakan konservasi lahan didaerah penelitian sebagian besar jenis konservasi lahannya dengan teras bangku dan hutan produksi dan sebagian kecil padang rumput, kebun campuran dan tanpa dilakukan tindakan konservasi.

Faktor erosivitas (R), erodibilitas tanah (K), Panjang lereng (L) dan kemiringan lereng (S), Vegetasi (C) dan Tindakan Konservasi tanah (P) dilakukan pengamatan secara langsung dan perhitungan menggunakan metode USLE untuk memperoleh nilai laju erosi tanah di Desa Bedoyo.

Tabel 1. Perhitungan Laju Erosi Tanah dengan Metode USLE

\begin{tabular}{|c|c|c|c|c|c|c|c|c|c|}
\hline No. & $\begin{array}{l}\text { Satuan } \\
\text { Lahan }\end{array}$ & $\mathrm{R}$ & $\mathrm{K}$ & LS & $\mathrm{C}$ & $\mathrm{P}$ & $\begin{array}{c}\mathrm{A} \\
\text { (ton/ha/Th) }\end{array}$ & $\begin{array}{l}\text { Kelas Bahaya } \\
\text { Erosi (KBE) }\end{array}$ & $\begin{array}{l}\text { Tingkat } \\
\text { Bahaya Erosi }\end{array}$ \\
\hline 1 & Lp1 & $3,161.107$ & 0,517 & 4.25 & 1,000 & 1,00 & 6.945 .742 & $\mathrm{~V}$ & Sangat Berat \\
\hline 2 & Lp2 & $3,161.107$ & 0,089 & 9.50 & 0,001 & 0,40 & 1.069 & I & Normal \\
\hline 3 & Lp3 & $3,161.107$ & 0,237 & 4.25 & 0,700 & 0,06 & 133.729 & III & Moderat \\
\hline 4 & Lp4 & $3,161.107$ & 0,442 & 4.25 & 0,001 & 0,40 & 2.375 & I & Normal \\
\hline 5 & Lp5 & $3,161.107$ & 0,071 & 4.25 & 0,200 & 0,60 & 114.464 & III & Moderat \\
\hline 6 & Lp6 & $3,161.107$ & 0,086 & 4.25 & 0,200 & 0,60 & 138.646 & III & Moderat \\
\hline 7 & Lp7 & $3,161.107$ & 0,247 & 9.50 & 0,200 & 0,10 & 148.351 & III & Berat \\
\hline 8 & Lp8 & $3,161.107$ & 0,716 & 9.50 & 1,000 & 1,00 & 21.501 .849 & $\mathrm{~V}$ & Sangat Berat \\
\hline 9 & Lp9 & $3,161.107$ & 0,222 & 4.25 & 0,700 & 0,06 & 125.265 & III & Moderat \\
\hline 10 & Lp10 & $3,161.107$ & 0,500 & 9.50 & 1,000 & 1,00 & 15.015 .258 & V & Sangat Berat \\
\hline
\end{tabular}

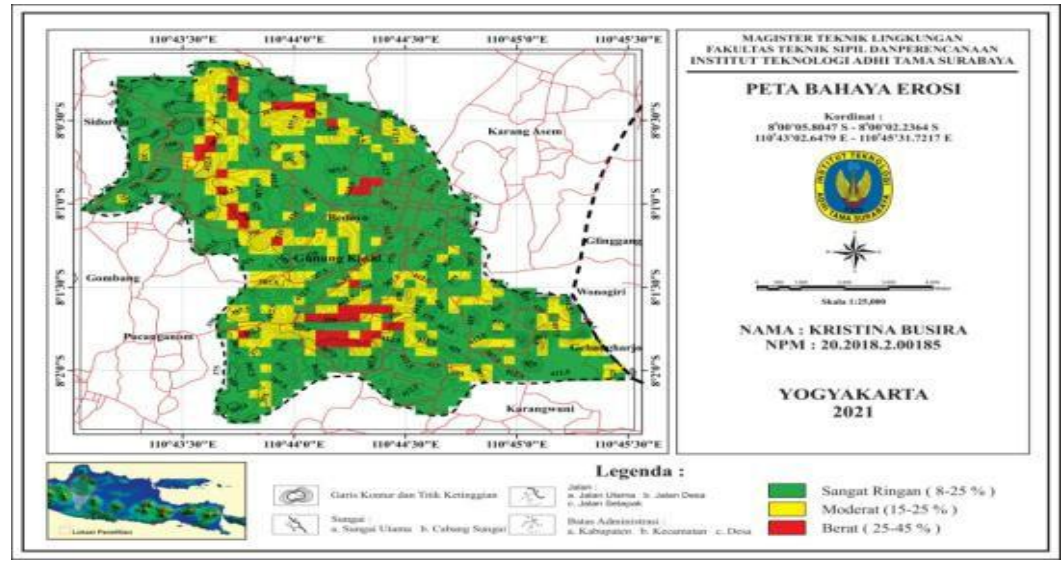

Gambar 4. Peta Tingkat Bahaya Erosi dengan Metode USLE

Nilai kedalaman dan resistivitas pada setiap lapisan batuan diperoleh berdasarkan hasil pengolahan data dari lapangan.
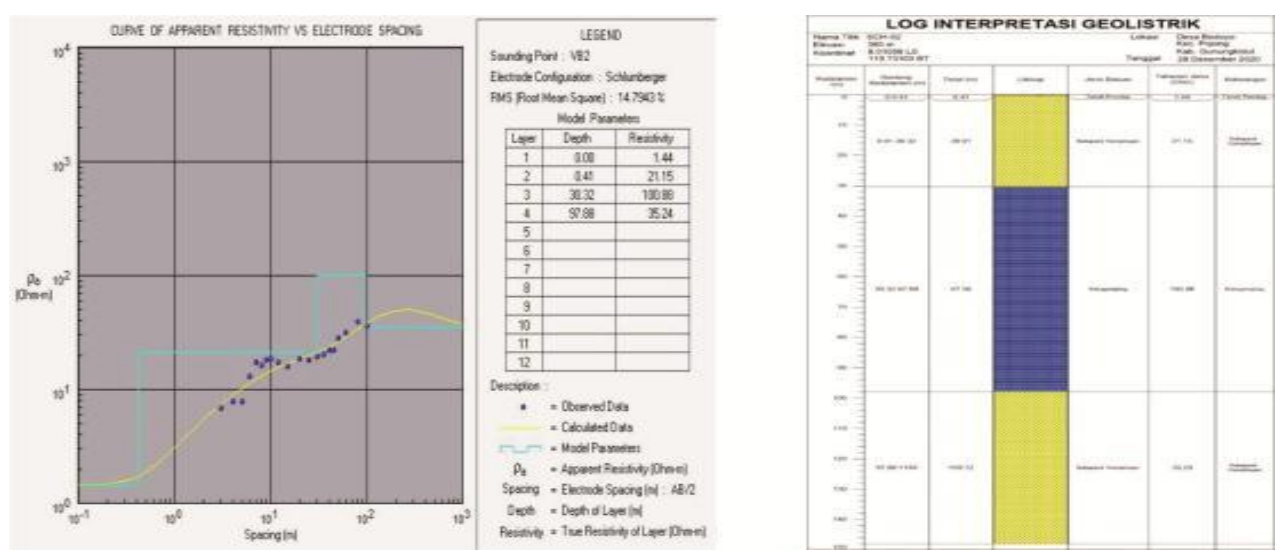

Gambar 5. Hasil pengolahan data geolistrik Section 1 


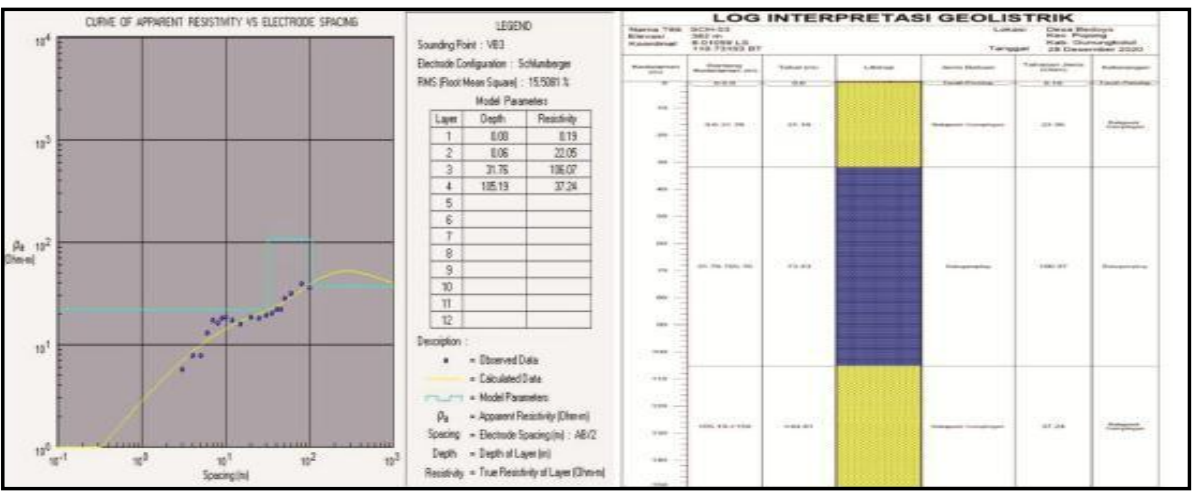

Gambar 6. Hasil pengolahan data geolistrik Section 2

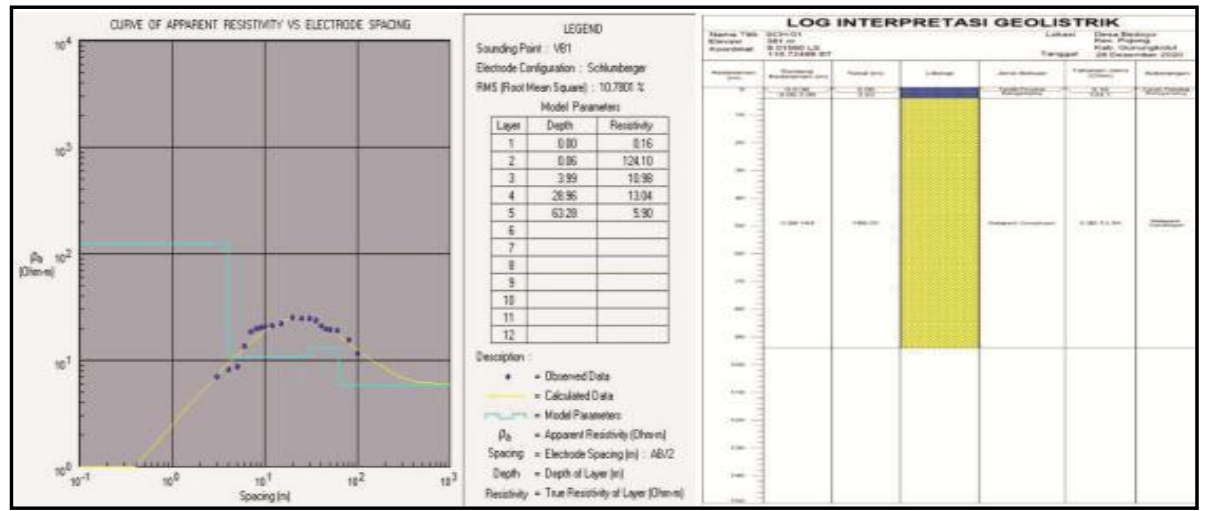

Gambar 7. Hasil pengolahan data geolistrik Section 3

Hasil interpretasi struktur lapisan batuan bawah permukaan berdasarkan nilai resistivitas di Desa Bedoyo, Pojong, Kabupaten Gunung Kidul, Daerah Istimewa Yogyakarta diperoleh tiga lapisan batuan penyusun bawah permukaan. Lapisan top soil, lapisan batupasir gampingan dan batu gamping. Lapisan batu gamping mempunyai variasi kedalaman dan ketebalan yang berbeda pada setiap titik sounding. Pada titik sounding Sch-1 pada kedalaman 0,06-3,99 meter, titik sounding Sch-2 pada kedalaman 30,32-97,88 meter, dan titik sounding Sch-3 pada kedalaman 31,76-105,19 meter.

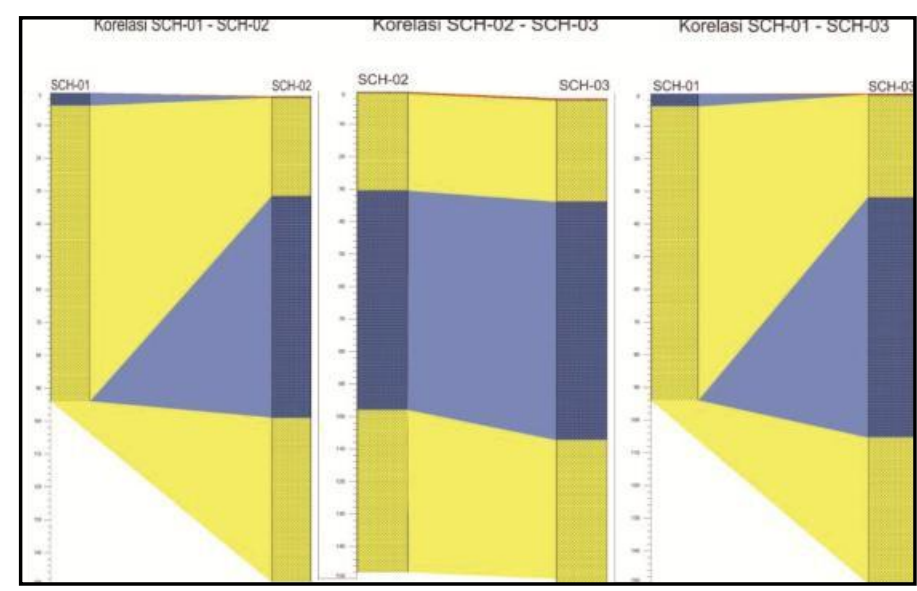

Gambar 8. Hasil korelasi geolistrik

\section{Kesimpulan}

Tingkat kerusakan lingkungan yang terjadi akibat penambangan batu gamping berdasarkan metode USLE diperoleh rata-rata dugaan erosi yang terjadi adalah $1.877,948$ ton/tahun. Tingkat bahaya erosi berdasarkan Departemen Kehutanan tahun 1998 adalah sangat berat, berat, moderat, dan 
normal. Arahan konservasi dilakukan berdasarkan tingkat bahaya erosi, yaitu (a) lahan tambang dan lahan bekas tambang agar dilakukan konservasi atau reklamasi vegetatif berupa tanaman penutup tanah seperti Rebah bangun (Mimosa invisa), Krokot (Alternanthera ticaina), Rumput teki (Cyperus rondentus). Sebelum dilakukan penanaman penggunaan mulsa, lebih utama agar menutup permukaan tanah, (b) hutan produksi jati agar ditanami dengan penanaman berganda seperti tebu karena perakaran dari tebu dapat menyerap air dan menambah bahan organik ke dalam tanah, dan (c) pada lahan yang mengalami tingkat erosi moderat disarankan melakukan penanaman berganda seperti tanaman ubi jalar karena tanaman ini perakarannya dapat menyerap air dengan unsur hara yang baik. Jenis akuifer yang telah teridentifikasi sangat dalam berada pada titik sounding Sch-2 dengan kedalaman 0,41-30,32 meter dan titik sounding Sch-3 dengan kedalaman 0,60-31,76 meter. Kedalaman air tanah yang berada di Desa Bedoyo cukup dalam karena dipengaruhi oleh lapisan batuan penyusun dan juga diperkirakan adanya kegiatan penambangan batu gamping.

\section{Referensi}

[1] Arsyad, S. 2010. Konservasi Tanah dan Air. IPB Press. Bogor.

[2] Manrulu, R.H. Aryadi Nurfalaq dan Iis, D.H., Pendugaan Sebaran Air Tanah Menggunakan Metode Geolistrik Resistivitas Konfigurasi Wenner dan Schlumberger Di Kampus 2 Universitas Cokroaminoto Palopo. Jurnal Fisika FLUX Volume 15, Nomor 1, ISSN : 1829- 796X.

[3] Widya Astuti. Himawati dan prof sutikno., 2007. Pengaruh Penambangan Batugampig Terhadap Air Tanah Di Desa Beoyo Kecamatan Ponjong Kabupaten Gunung Kidul Daerah Istemewa Yogyakarta. Tesis S2 Ilmu Lingkungan UGM. 